\title{
Hospital waste water: health risk for human and environment by cytostatic drug emissions? Part I: Model calculation and chemical monitoring
}

\author{
Maria Fuerhacker ${ }^{1}$, Susanne N Mahnik ${ }^{1,2}$, Katharina Lenz ${ }^{1}$, \\ Norbert Weissenbacher ${ }^{1}$, Robert M Mader ${ }^{2}$, Petra Krenn ${ }^{2}$, Stephan Hann ${ }^{1}$, \\ Gunda Koellensperger ${ }^{1}$, Maria Uhl ${ }^{3}$, Siegfried Knasmüller ${ }^{2}$, Franziska Ferk ${ }^{2}$ \\ and Wilfried Bursch*2
}

Address: ${ }^{1}$ BOKU University of Natural Resources and Applied Life Sciences, Vienna, Austria, ${ }^{2}$ Institute of Cancer Research, Clinics of Internal Medicine I, Medical University of Vienna, Austria and ${ }^{3}$ Umweltbundesamt, Vienna, Austria

Email: Wilfried Bursch* - wilfried.bursch@meduniwien.ac.at

* Corresponding author

\begin{abstract}
from I3th Scientific Symposium of the Austrian Pharmacological Society (APHAR). Joint Meeting with the Austrian Society of Toxicology (ASTOX) and the Hungarian Society for Experimental and Clinical Pharmacology (MFT)

Vienna, Austria. 22-24 November 2007

Published: 14 November 2007

BMC Pharmacology 2007, 7(Suppl 2):A69 doi:10.1 I86/I47|-2210-7-S2-A69
\end{abstract}

This abstract is available from: http://www.biomedcentral.com//47I-22/0/7/S2/A69

(c) 2007 Fuerhacker et al; licensee BioMed Central Ltd.

\section{Project}

"Chemical analysis, risk assessment and elimination of selected cytostatic agents from hospital waste water", performed at the University Hospital (AKH) Vienna.

\section{Methods}

Drugs: 5-fluorouracil, doxorubicin, epirubicin, daunorubicin, cisplatin, carboplatin, oxaliplatin. Model calculation: Minimum, maximum annual average concentrations and cumulative amount in hospital sewage were calculated. Parameters: drug, water consumption in the oncologic in-patient treatment ward, renal human excretion rate. Chemical analysis: platinum compounds: ICP-MS (speciation analysis by on-line coupling of HPLC to ICP-MS $)$, limits of detection: cisplatin $(0.09 \mu \mathrm{g} / \mathrm{l})$, carboplatin $(0.1 \mu \mathrm{g} / \mathrm{l})$, oxaliplatin $(0.15 \mu \mathrm{g} / \mathrm{l})$. Anthracyclines: solid phase extraction, HPLC and fluorescence detection (FLD), limits of detection: doxorubicin (0.05 $\mu \mathrm{g} / \mathrm{l})$, daunorubicin $(0.06 \mu \mathrm{g} / \mathrm{l})$. 5-Fluorouracil: solid phase extraction, capillary electrophoresis, limit of detection $1.7 \mu \mathrm{g} / \mathrm{l}$. Chemical monitoring: waste water samples: effluent of (a) the total hospital (TH), (b) the oncological ward (OW), collected before dilution in the Vienna sewer system for a total period of 98 days.

\section{Results}

Pt concentrations ranged from 3.2 to $266 \mu \mathrm{g} / \mathrm{l}$; estimates revealed that about one third of the administered drugs was detected in the waste water of the oncologic ward. 5Fluorouracil was detected in waste water up to $124 \mu \mathrm{g} / \mathrm{l}$, doxorubicin up to $1.35 \mu \mathrm{g} / \mathrm{l}$. The concentrations determined chemically agreed with the predictions based upon model calculations. 